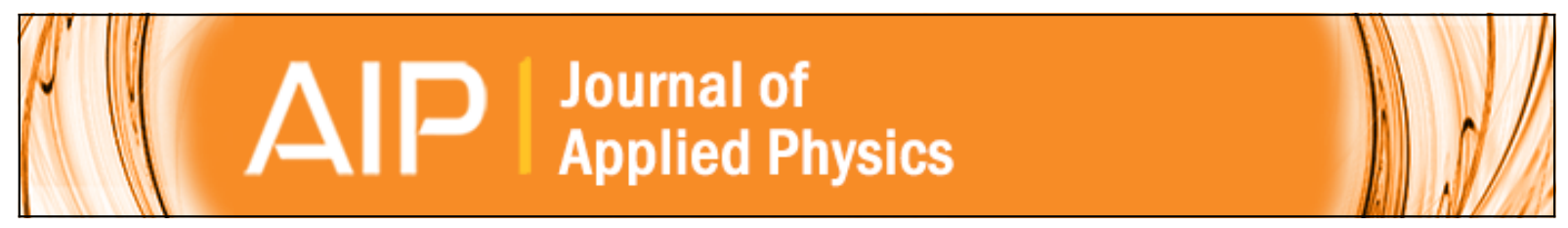

\title{
Formation characteristics and photoluminescence of Ge nanocrystals in HfO 2
}

Sung Kim, Sung Won Hwang, Suk-Ho Choi, R. G. Elliman, Young-Min Kim, and Youn-Joong Kim

Citation: Journal of Applied Physics 105, 106112 (2009); doi: 10.1063/1.3132797

View online: http://dx.doi.org/10.1063/1.3132797

View Table of Contents: http://scitation.aip.org/content/aip/journal/jap/105/10?ver=pdfcov

Published by the AIP Publishing

\section{Articles you may be interested in}

Microstructural characteristics and phonon structures in luminescence from surface oxidized Ge nanocrystals embedded in HfO 2 matrix

J. Appl. Phys. 108, 053510 (2010); 10.1063/1.3475717

Light emission and photoluminescence from high- $k$ dielectrics containing Ge nanocrystals

J. Vac. Sci. Technol. B 27, 535 (2009); 10.1116/1.3025844

Ultraviolet and blue photoluminescence from sputter deposited Ge nanocrystals embedded in SiO 2 matrix J. Appl. Phys. 103, 103534 (2008); 10.1063/1.2930877

Improved charge injection characteristics of Ge nanocrystals embedded in hafnium oxide for floating gate devices

Appl. Phys. Lett. 91, 233118 (2007); 10.1063/1.2821114

Coexisting photoluminescence of Si and Ge nanocrystals in Ge/Si thin film

J. Appl. Phys. 90, 5318 (2001); 10.1063/1.1412269
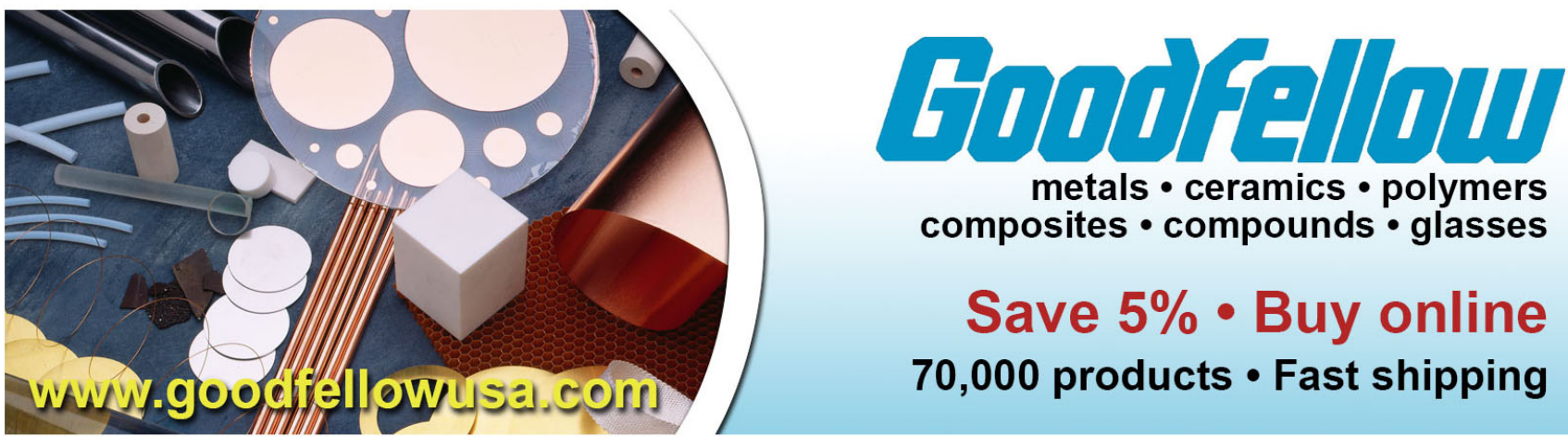


\title{
Formation characteristics and photoluminescence of Ge nanocrystals in $\mathrm{HfO}_{2}$
}

\author{
Sung Kim, ${ }^{2}$ Sung Won Hwang, ${ }^{1}$ Suk-Ho Choi, ${ }^{1, a)}$ R. G. Elliman, ${ }^{2}$ Young-Min Kim, ${ }^{3}$ and \\ Youn-Joong Kim ${ }^{3}$ \\ ${ }^{1}$ Department of Applied Physics, College of Applied Sciences, Kyung Hee University, Yongin 449-701, \\ Republic of Korea \\ ${ }^{2}$ Department of Electronic Materials Engineering, Research School of Physical Sciences and Engineering, \\ Australian National University, Canberra ACT 0200, Australia \\ ${ }^{3}$ Division of Electron Microscopic Research, Korea Basic Science Institute, Daejeon 305-333, \\ Republic of Korea
}

(Received 31 January 2009; accepted 18 April 2009; published online 28 May 2009)

Ge nanocrystals (NCs) are shown to form within $\mathrm{HfO}_{2}$ at relatively low annealing temperatures $\left(600-700{ }^{\circ} \mathrm{C}\right)$ and to exhibit characteristic photoluminescence (PL) emission consistent with quantum confinement effects. After annealing at $600^{\circ} \mathrm{C}$, sample implanted with 8.4 $\times 10^{15} \mathrm{Ge} \mathrm{cm}^{-2}$ show two major PL peaks, at 0.94 and $0.88 \mathrm{eV}$, which are attributed to no-phonon and transverse-optical phonon replica of Ge NCs, respectively. The intensity reaches a maximum for annealing temperatures around $700{ }^{\circ} \mathrm{C}$ and decreases at higher temperatures as the NC size continues to increase. The no-phonon emission also undergoes a significant redshift for temperatures above $800{ }^{\circ} \mathrm{C}$. For fluences in the range from $8.4 \times 10^{15}$ to $2.5 \times 10^{16} \mathrm{~cm}^{-2}$, the average NC size increases from $\sim 13.5 \pm 2.6$ to $\sim 20.0 \pm 3.7 \mathrm{~nm}$. These $\mathrm{NC}$ sizes are much larger than within amorphous $\mathrm{SiO}_{2}$. Implanted $\mathrm{Ge}$ is shown to form Ge NCs within the matrix of monoclinic $(m)-\mathrm{HfO}_{2}$ during thermal annealing with the orientation relationship of $[101] m-\mathrm{HfO}_{2} / /[110] \mathrm{Ge} \mathrm{NC}$. (C) 2009 American Institute of Physics. [DOI: 10.1063/1.3132797]

Nanocrystal (NC) floating gate memories (NFGM) have received considerable attention as one of the most promising candidates for future nonvolatile, high-density, and lowpower flash memory devices. ${ }^{1,2}$ Both semiconducting and metallic NCs have been considered for charge storage. ${ }^{1-3}$ Of the semiconductor candidates, $\mathrm{Ge}$ is of particular interest because NCs can be formed at relatively low temperatures $\left(800-900{ }^{\circ} \mathrm{C}\right)$ and have a small bandgap. ${ }^{4}$ The continued scaling of complementary metal-oxide-silicon (CMOS) technology has also recently seen a shift to high-dielectricconstant (high- $k$ ) dielectrics as a replacement for $\mathrm{SiO}_{2}$ as the gate dielectrics. ${ }^{5}$ Hf-based oxides are one of the most attractive high- $k$ dielectrics due to their high permittivity and compatibility with CMOS processing. ${ }^{6}$ This has led to an interest in the formation of $\mathrm{NCs}$ within $\mathrm{HfO}_{2}$, including $\mathrm{Ge} \mathrm{NCs}$, for advanced CMOS technology. ${ }^{7}$ The size and density of Ge NCs or SiGe nanodots (NDs) are known to be distributed nonuniformly within amorphous $\mathrm{SiO}_{2}$ matrix due to the high diffusivity of $\mathrm{Ge}$ atoms. ${ }^{8,9}$ In contrast, nucleation or aggregation of Ge atoms within Hf-based high- $k$ matrix would be strongly influenced by the crystallization of the high- $k$ matrix during thermal annealing because the Hf-based oxides are crystallized at lower temperatures than Ge. There have been almost no systematic studies on the growth and optical properties of Ge NCs within high- $k$ dielectrics despite intense research on their NFGM application. In this communication, we report the growth and optical characteristics of Ge NCs formed within $\mathrm{HfO}_{2}$ by $\mathrm{Ge}^{-}$ion implantation and annealing.

\footnotetext{
a) Author to whom correspondence should be addressed. Electronic mail: sukho@khu.ac.kr.
}

A $5 \mathrm{~nm} \mathrm{SiO}_{2}$ layer was first grown on $p$-type (100) $\mathrm{Si}$ wafer by conventional thermal oxidation. A $25 \mathrm{~nm} \mathrm{HfO}_{2}$ layer was then grown on top of the $\mathrm{SiO}_{2}$ layer by atomic layer deposition. These $\mathrm{Si} / \mathrm{SiO}_{2} / \mathrm{HfO}_{2}$ structures were implanted at room temperature (RT) with $\mathrm{Ge}^{-}$ions of $15 \mathrm{keV}$ to nominal fluences $\left(n_{\mathrm{Ge}}\right)$ of $8.4 \times 10^{15}, 1.7 \times 10^{16}$, and 2.5 $\times 10^{16} \mathrm{~cm}^{-2}$ and subsequently annealed at temperatures $\left(T_{A}\right)$ in the range from 600 to $1000{ }^{\circ} \mathrm{C}$ for $5 \mathrm{~min}$ in a $\mathrm{N}_{2}$ atmosphere. The peak excess Ge concentration for these implants was calculated from TRIM simulation to be around 27 at. \% for the highest fluence employed. ${ }^{10} \mathrm{X}$-ray photoelectron spectroscopy (XPS) measurements were carried out at RT in the energy of $250 \mathrm{eV}$ at the 7B1 beamline of Pohang Accelerator Laboratory with a base pressure of $1.5 \times 10^{-10}$ torr. Details of the XPS measurements are described elsewhere. ${ }^{11}$ PL (photoluminescence) sectra were measured at $15 \mathrm{~K}$ using the $488 \mathrm{~nm}$ line of an $\mathrm{Ar}^{+}$laser as the excitation source and a liquid nitrogen cooled Ge detector. Standard lock-in detection techniques were used to maximize the signal-to-noise ratio. The laser beam diameter was about $300 \mu \mathrm{m}$ and the power was about $50 \mathrm{~mW}$.

Figure 1 shows XPS spectra of Ge $3 d$ and $\mathrm{O} 2 s$ core levels for Ge-implanted $\mathrm{HfO}_{2}\left(\mathrm{HfO}_{2}: \mathrm{Ge}\right)$ with a Ge fluence of $8.4 \times 10^{15} \mathrm{~cm}^{-2}$ before and after annealing. The asimplanted sample shows XPS peaks of Ge $3 d$ and O $2 s$ levels at 30.8 and $23.2 \mathrm{eV}$, respectively. ${ }^{12}$ Five oxidation states, $\mathrm{Ge}^{n+}(n=0-4)$ responsible for the Ge $3 d$ XPS peak could exist in Ge-implanted oxides. ${ }^{12-14}$ The Ge $3 d$ XPS peaks from crystalline $\mathrm{Ge}$ and $\mathrm{GeO}_{2}$ are usually observed at $\sim 29.3$ and $\sim 32.5 \mathrm{eV}$, respectively, as indicated in Fig. 1. ${ }^{12}$ The shift of the Ge $3 d$ peak (with respect to $\mathrm{Ge}^{0}$ ) has previously been attributed to $\mathrm{Ge}-\mathrm{O}$, $\mathrm{Ge}-\mathrm{Hf}-\mathrm{O}$ and $\mathrm{Ge}-\mathrm{Hf}$ bonds, as 


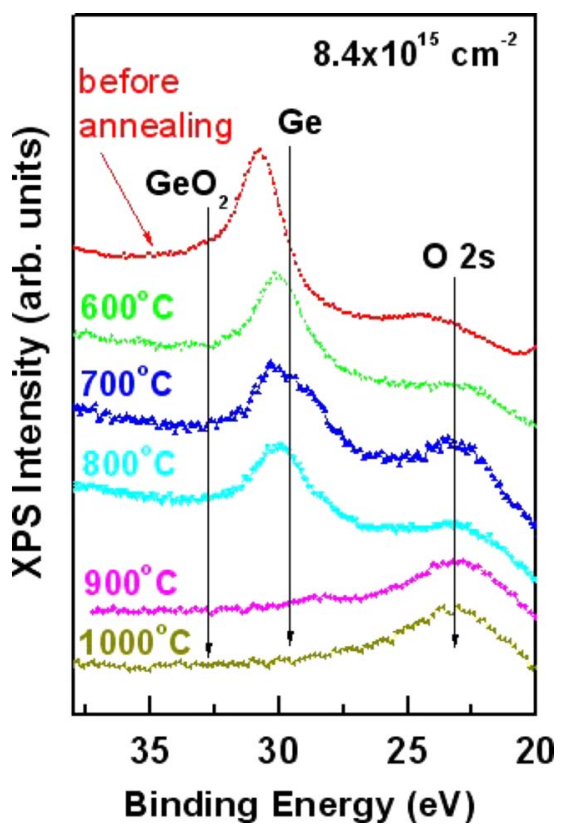

FIG. 1. (Color online) XPS spectra of Ge $3 d$ and O $2 s$ core levels for $\mathrm{HfO}_{2}$ : Ge films with a Ge fluence of $8.4 \times 10^{15} \mathrm{~cm}^{-2}$ before and after annealing.

shown in a study of the $\mathrm{Ge} / \mathrm{HfO}_{2}$ interface ${ }^{12}$ or to $\mathrm{Ge}$ suboxides. ${ }^{13,14}$ The Ge $3 d$ XPS peak $(30.8 \mathrm{eV})$ from the asimplanted sample is also therefore attributed to the Ge suboxide phase and/or $\mathrm{Ge}-\mathrm{Hf}-\mathrm{O} / \mathrm{Ge}-\mathrm{Hf}$ bonds. After annealing at $600{ }^{\circ} \mathrm{C}$ the $\mathrm{Ge} 3 d$ peak shifts to lower energy, consistent with the formation of elemental-Ge NCs. Similar peaks are observed for samples annealed at temperatures in the range from 600 to $800{ }^{\circ} \mathrm{C}$ suggesting that stable Ge NCs are formed in this temperature range. However, for $T_{A}$ $\geq 900{ }^{\circ} \mathrm{C}$ the Ge $3 d$ peak disappears, suggesting that $\mathrm{Ge}$ is no longer present in the near surface region.

Figure 2 compares infrared (IR) PL spectra from Geimplanted $\mathrm{HfO}_{2}$ after annealing at $700{ }^{\circ} \mathrm{C}$ with those of un-

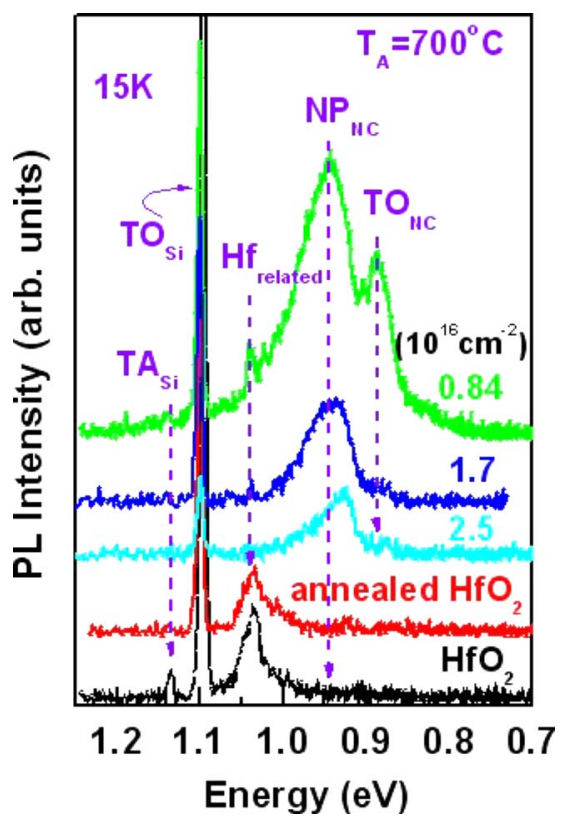

FIG. 2. (Color online) IR PL spectra of $\mathrm{HfO}_{2}$ : Ge films at each $n_{\mathrm{Ge}}$ after annealing at $700{ }^{\circ} \mathrm{C}$ together with those of untreated and annealed $\mathrm{HfO}_{2}$ layers.

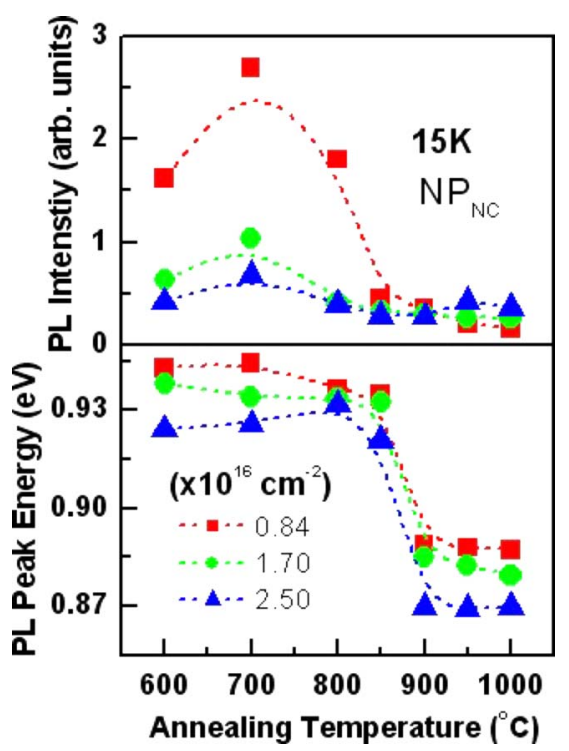

FIG. 3. (Color online) Annealing temperature-dependent PL peak intensities and energies of $\mathrm{HfO}_{2}$ : Ge films at each $n_{\mathrm{Ge}}$.

treated and annealed $\mathrm{HfO}_{2}$ layers. The $1.03 \mathrm{eV}$ PL peak observed in unimplanted and implanted $\mathrm{HfO}_{2}$ samples is attributed to native defects in $\mathrm{HfO}_{2}$, possibly including metallic $\mathrm{Hf}^{13}$ and the 1.10 and $1.13 \mathrm{eV}$ peaks are attributed to the transverse optical $\left(\mathrm{TO}_{\mathrm{Si}}\right)$ and acoustical $\left(\mathrm{TA}_{\mathrm{Si}}\right)$ transitions in the $\mathrm{Si}$ substrate, respectively. Two additional peaks are observed for Ge-implanted samples, one at 0.94 and one at $0.88 \mathrm{eV}$. These are most evident for the sample implanted with $8.4 \times 10^{15} \mathrm{Ge} \mathrm{cm}^{-2}$ and are observed to redshift and decrease in intensity as the Ge implant fluence is increased. The two peaks are attributed to the no-phonon $\left(\mathrm{NP}_{\mathrm{NC}}\right)$ and transverse-optical $\left(\mathrm{TO}_{\mathrm{NC}}\right)$ phonon replica from $\mathrm{Ge} \mathrm{NCs}$, respectively, as reported for Ge $\mathrm{NCs}$ in $\mathrm{SiO}_{2} .{ }^{15}$ The observed redshift and the reduction in intensity can be attributed to an increase in the average size of Ge NCs at higher implant fluences. ${ }^{15}$ Visible PL emission is also observed from these samples but this is not readily correlated with the presence of the NCs.

Figure 3 summarizes the effect of annealing temperature on the Ge-related PL emission (i.e., the $\mathrm{NP}_{\mathrm{NC}}$ peak). The data clearly show that the PL intensity increases for samples annealed at temperatures up to $700{ }^{\circ} \mathrm{C}$ and then decreases rapidly for samples annealed at higher temperatures, and that the emission also undergoes a significant redshift for temperatures above $800{ }^{\circ} \mathrm{C}$. Both of these effects are consistent with an increase in the average size of Ge NCs at higher temperatures. ${ }^{8}$ The synthesis of Ge NCs proceeds by nucleation, growth, and Ostwald ripening, and depends on the solubility and diffusivity of $\mathrm{Ge}$ in the host material and on the Ge concentration, concentration profile, annealing temperature, and annealing ambient. ${ }^{7,9}$ The optimum temperature for the formation of Ge $\mathrm{NCs}$ in $\mathrm{SiO}_{2}$ is known to be within the range of the bulk melting point $(\sim 937) \pm 235{ }^{\circ} \mathrm{C} .{ }^{16}$ The present study shows that this temperature is much lower (i.e., $600-700{ }^{\circ} \mathrm{C}$ ) in $\mathrm{HfO}_{2}$.

Figure 4(a) shows cross-sectional high-resolution transmission electron microscopy (HRTEM) images taken along the (110) zone axis of a $\mathrm{HfO}_{2}$ grain for a sample implanted 


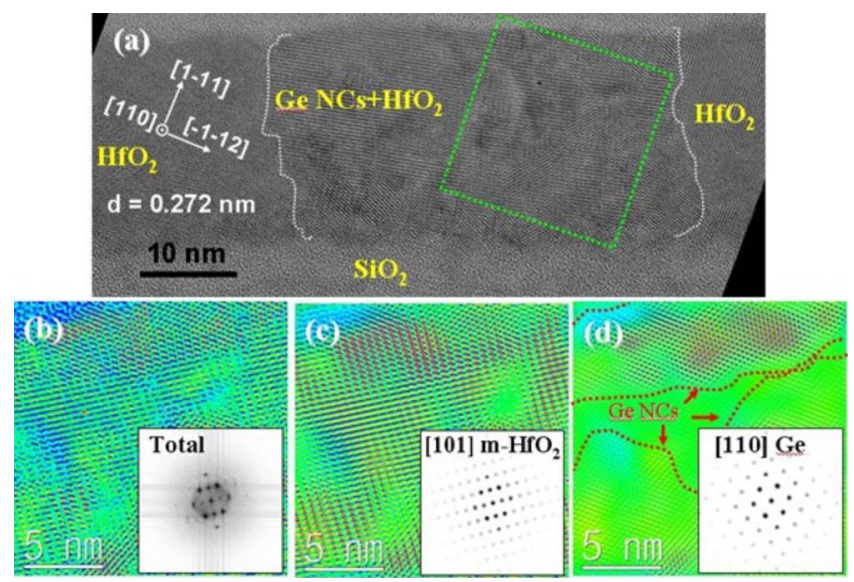

FIG. 4. (Color online) (a) Cross-sectional HRTEM image taken along the (110) zone axis for $\mathrm{HfO}_{2}$ : Ge films with a fluence of $8.4 \times 10^{15} \mathrm{~cm}^{-2}$ after annealing at $700{ }^{\circ} \mathrm{C}$. [(b)-(d)] IFFT images and diffractograms (insets) corresponding to $m-\mathrm{HfO}_{2}+\mathrm{Ge} \mathrm{NC,} m-\mathrm{HfO}_{2}$, and $\mathrm{Ge} \mathrm{NC}$, respectively.

with $8.4 \times 10^{15} \mathrm{Ge} \mathrm{cm}^{-2}$ after annealing at $700{ }^{\circ} \mathrm{C}$. The $\mathrm{HfO}_{2}$ : Ge layer consists of nanocrystalline grains having a lattice spacing $d$ of about $0.272 \mathrm{~nm}$ and corresponding to the monoclinic $(m-)$ phase of typical $\mathrm{HfO}_{2}{ }^{5}$ This particular grain contains $\mathrm{Ge} \mathrm{NCs}$, which are more clearly delineated in the processed images depicted in Figs. 4(b)-4(d). Specifically, Fig. 4(b) shows an enlarged image of the region defined by the square together with its diffractogram (as an inset), which represents the superimposition of images from $m-\mathrm{HfO}_{2}$ and $\mathrm{Ge} \mathrm{NCs}$. Fourier mask filtering techniques ${ }^{17}$ were employed to distinguish the Ge NCs from the $m-\mathrm{HfO}_{2}$ and the filtered diffractograms and HRTEM images from their inverse fast Fourier transforms (IFFTs) reflect the separated image amplitudes generated from the $[101] m-\mathrm{HfO}_{2}$ and [110] Ge NC, as shown in Figs. 4(c) and 4(d), respectively. The IFFT result of [101] $m$ - $\mathrm{HfO}_{2}$ in Fig. 4(c) is similar to that of the composite image in Fig. 4(b), indicating that the matrix can be regarded as $m-\mathrm{HfO}_{2}$ structure. However, the HRTEM image generated from the IFFT of [110] Ge diffractogram shows regions of confined image amplitude within several tens nanometers corresponding to the Ge NC, as indicated by the dotted lines in Fig. 4(d). These results suggest that implanted Ge forms Ge NCs within the matrix of $m-\mathrm{HfO}_{2}$ during thermal annealing with the orientation relationship of $[101] m-\mathrm{HfO}_{2} / /[110] \mathrm{Ge} \mathrm{NC}$.

These nanostructures are repeated through the whole area of the samples, as confirmed by HRTEM. For samples annealed at $700{ }^{\circ} \mathrm{C}$, the average size of the $\mathrm{Ge}$ NCs was estimated to be $\sim 13.5 \pm 2.6 \mathrm{~nm}$ for a Ge fluence of 8.4 $\times 10^{15} \mathrm{~cm}^{-2}$, and increased monotonically with increasing Ge fluence to $\sim 20.0 \pm 3.7 \mathrm{~nm}$ for a fluence of 2.5 $\times 10^{16} \mathrm{~cm}^{-2}$. These NC sizes are much larger than within amorphous $\mathrm{SiO}_{2}$. Before annealing, the $\mathrm{HfO}_{2}$ : Ge shows two secondary ion mass spectrometry (SIMS) peaks, (the data were not shown here) among which one in $\mathrm{HfO}_{2}$ layer is much larger than the other in $\mathrm{SiO}_{2}$ layer. During annealing, the Ge atoms within $\mathrm{HfO}_{2}$ form Ge NCs while the Ge SIMS peak moves a very slight distance of $\sim 1.5 \mathrm{~nm}$ toward the $\mathrm{HfO}_{2} / \mathrm{SiO}_{2}$ interface with almost no change of its intensity, indicating little long-range diffusion of $\mathrm{Ge}$ atoms within
$\mathrm{HfO}_{2}$. In contrast, the Ge SIMS peak within $\mathrm{SiO}_{2}$ diffuses considerably to the $\mathrm{SiO}_{2} / \mathrm{Si}$ interface or even into the $\mathrm{Si}$ substrate by the annealing. Ge NCs or NDs usually show nonuniform distribution of size and density within $\mathrm{SiO}_{2}$ due to the high diffusion rate of $\mathrm{Ge}$ atoms, ${ }^{8,9}$ consistent with our results. The crystallization of $\mathrm{HfO}_{2}$ would facilitate the aggregation of Ge atoms by driving them away from the $\mathrm{HfO}_{2}$ region, resulting in the $\mathrm{NC}$ formation at lower temperature as $\sim 700{ }^{\circ} \mathrm{C}$. In addition to this effect, the little long-range diffusion of $\mathrm{Ge}$ atoms within $\mathrm{HfO}_{2}$ would also help Ge NCs grow larger than within $\mathrm{SiO}_{2}$.

In summary, Ge $\mathrm{NCs}$ were formed within $\mathrm{HfO}_{2}$ by $\mathrm{Ge}^{-}$-ion implantation and relatively low temperature $\left(600-700{ }^{\circ} \mathrm{C}\right)$ annealing. As the implant fluence increased from $8.4 \times 10^{15}$ to $2.5 \times 10^{16} \mathrm{~cm}^{-2}$ the size of the Ge NCs increased from $13.5 \pm 2.6$ to $\sim 20.0 \pm 3.7 \mathrm{~nm}$. These NC sizes are much larger than within amorphous $\mathrm{SiO}_{2}$. PL emission attributable to the Ge NCs was observed in the implanted and annealed samples and this was shown to have a maximum intensity after annealing at $700{ }^{\circ} \mathrm{C}$. The PL emission exhibited a redshift and a reduction in intensity as the average size of the NCs increased for annealing temperatures above $700{ }^{\circ} \mathrm{C}$. Implanted $\mathrm{Ge}$ was shown to form Ge NCs within the matrix of $m-\mathrm{HfO}_{2}$ with the orientation relationship of $[101] m-\mathrm{HfO}_{2} / /[110] \mathrm{Ge} \mathrm{NC}$.

S.H.C. and R.G.E. acknowledge supports from the Korea Research Foundation Grant (Grant No. KRF-2007-521C00094) and from the Australian Research Council (Discovery Project), respectively.

${ }^{1}$ K. I. Han, Y. M. Park, S. Kim, S.-H. Choi, K. J. Kim, I. H. Park, and B.-G. Park, IEEE Trans. Electron Devices 54, 359 (2007).

${ }^{2}$ C. J. Park, H. Y. Cho, S. Kim, S.-H. Choi, R. G. Elliman, J. H. Han, C. Kim, H. N. Hwang, and C. C. Hwang, Appl. Phys. Lett. 99, 036101 (2006).

${ }^{3}$ K. S. Seol, K. S. Cho, B.-K. Kim, J.-Y. Choi, E.-K. Lee, Y.-S. Min, J.-B. Park, and S.-H. Choi, J. Korean Phys. Soc. 50, 49 (2007).

${ }^{4}$ M. Kanoun, A. Souifi, T. Baron, and F. Mazen, Appl. Phys. Lett. 84, 5079 (2004).

${ }^{5}$ J. E. Jaffe, R. A. Bachorz, and M. Gutowski, Phys. Rev. B 72, 144107 (2005).

${ }^{6}$ K.-I. Seo, D.-I. Lee, P. Pianetta, H. Kim, K. C. Saraswat, and P. C. Mclntyre, Appl. Phys. Lett. 89, 142912 (2006).

${ }^{7}$ F. Zheng, H. G. Chew, W. K. Choi, J. X. Zhang, and H. L. Seng, J. Appl. Phys. 101, 114310 (2007).

${ }^{8}$ X. L. Wu, T. Gao, X. M. Bao, F. Yan, S. S. Jiang, and D. Feng, J. Appl. Phys. 82, 2704 (1997).

${ }^{9}$ W. K. Choi, V. Ho, V. Ng, Y. W. Ho, S. P. Ng, and W. K. Chim, Appl. Phys. Lett. 86, 143114 (2005).

${ }^{10}$ J. P. Biersack and L. G. Haggmark, Nucl. Instrum. Methods 174, 257 (1980).

${ }^{11}$ S. Kim, M. C. Kim, S.-H. Choi, K. J. Kim, H. N. Hwang, and C. C. Hwang, Appl. Phys. Lett. 91, 103113 (2007).

${ }^{12}$ J. Zuk, H. Krzyzanowska, M. J. Clouter, M. Bromberek, H. Bubert, L. Rebohle, and W. Skorupa, J. Appl. Phys. 96, 4952 (2004).

${ }^{13}$ G. Pourtois, M. Houssa, A. Delable, T. Conard, M. Caymax, M. Meuris, and M. M. Heyns, Appl. Phys. Lett. 92, 032105 (2008).

${ }^{14}$ A. Molle, Md. N. K. Bhulyan, G. Tallarida, and M. Fanclulli, Appl. Phys. Lett. 89, 083504 (2006).

${ }^{15}$ S. Takeoka, M. Fujji, S. Hayashi, and K. Yamamoto, Phys. Rev. B 58, 7921 (1998).

${ }^{16}$ Q. Xu, L. D. Sharp, C. W. Yuan, D. O. Yi, C. Y. Liao, A. M. Glaeser, A. M. Minor, J. W. Beeman, M. C. Ridgway, P. Kluth, J. W. Ager III, D. C. Chrzan, and E. E. Haller, Phys. Rev. Lett. 97, 155701 (2006).

${ }^{17}$ Y.-M. Kim, J.-M. Jeong, J.-G. Kim, Y.-J. Kim, and Y. S. Lim, J. Korean Phys. Soc. 48, 250 (2006). 